\title{
Correspondence
}

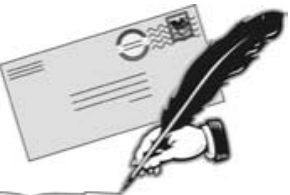

\section{Must the entive brain be dead to diagnose brain death?}

To the Editor:

The June 2006 issue of the Canadian Journal of Anesthesia contains four excellent articles dealing with brain death. ${ }^{1-4}$ In 1981 the President's Commission for the Study of Ethical Problems in Medicare and Biomedical and Behavioral Research published a landmark report intended to establish a common ground for American law related to brain death. ${ }^{5}$ The commission defined brain death as the "irreversible cessation of all functions of the entire brain, including the brain stem". Since that time, this seminal report has been used as the basis for much of the discourse on brain death, especially in the United States. Similarly, the World Medical Association has written that "it is essential to determine the irreversible cessation of all functions of the entire brain, including the brain stem". ${ }^{6}$

The purpose of this letter is to point out that, while these bodies have defined brain death in terms of "irreversible cessation of all functions of the entive brain," in the years since this definition has been widely adopted it has become very clear that many (perhaps most) patients diagnosed with brain death do not actually meet this requirement. In particular, many patients diagnosed with brain death still synthesize arginine vasopressin (which regulates serum osmolality), implying the presence of residual function in the hypothalmus. Indeed, evaluation of hypothalamic function is not part of any brain death protocol with which I am familiar. It may be time for the World Medical Association and other authorities to reformulate the definition of brain death to reflect current clinical realities.

D. John Doyle MD PhD FRCPC

Cleveland Clinic Foundation, Cleveland, USA

E-mail: doylej@ccf.org

Accepted for publication August 4, 2006.

\section{References}

1 Baron L, Shemie SD, Teitelbaum J, Doig CJ. Brief review: History, concepts and controversies in the neurological determination of death. Can J Anesth 2006; 53: 602-8.
2 Doig CJ, Young K, Teitelbaum J, Shemie SD. Brief survey: Determining brain death in Canadian intensive care units. Can J Anesth 2006; 53: 609-12.

3 Hornby K, Shemie SD, Teitelbaum J, Doig C. Variability in hospital-based brain death guidelines in Canada. Can J Anesth 2006; 53: 613-9.

4 Young GB, Shemie SD, Doig CJ, Teitelbaum J. Brief review: The role of ancillary tests in the neurological determination of death. Can J Anesth 2006; 53 : 620-7.

5 President's Commission for the Study of Ethical Problems in Medicine and Biomedical and Behavior Research: Defining Death: A Report on the Medical, Legal and Ethical Issues in the Determination of Death. Washington, DC, US Government Printing Office, 1981.

6 World Medical Association Declaration on Death. Available from URL; http://www.wma.net/e/policy/ d2.htm.

Reply:

I thank Dr. Doyle for raising important and fundamental issues that are a source of confusion in theory and bedside practice. Does the term "brain death" refer to death of the brain itself, or does it refer to death as determined by the loss of neurological function? The answer depends on which concept of brain death is accepted, and this varies according to jurisdiction. In the United States, a whole brain definition (cerebral hemispheres and brainstem) for brain death is codified based on the irreversible cessation of all functions of the brain, including the brainstem. This is distinct from the United Kingdom where a brainstem-based definition of death is applied.

In brain injury associated with mass effect or generalized edema, loss of whole brain function usually occurs by the sequence of elevated intracranial pressure, rostral-caudal brainstem herniation and cerebrocirculatory arrest. However, complete and irreversible loss of brainstem function may be seen in isolated brainstem injury without the typical herniation sequence (e.g., massive brainstem infarction) which may or may not be accompanied by complete loss of cerebral hemispheric function. The mechanism of loss of consciousness in brainstem death is related to interruption of the ascending reticular activating system. 
It must be understood that the clinical evaluation for loss of neurological function in brain death examinations only detects the absence of brainstem function. This comprises the loss of consciousness and the absence of brainstem reflexes, including the capacity to breathe. The clinical examination cannot distinguish the complete loss of whole brain function from the isolated loss of brainstem function. The distinction between whole brain and brainstem death can be made based on etiology of brain injury and neuroimaging. It can only be confirmed by the use of ancillary tests that show an absence of electroencephalographic activity, or preferably, the absence of intracerebral blood flow. For this reason, ancillary testing is used frequently in the United States but only rarely in the United Kingdom.

Dr. Doyle and others ${ }^{l}$ suggest that laboratory evidence of retained hypothalamic-pituitary activity is inconsistent with the whole-brain formulation. Bernat ${ }^{2}$ rejects laboratory evidence of cellular function, arguing that isolated cellular activity may persist in the absence of clinical signs of brain activity. While intracerebral blood flow arrests in whole brain death, small degrees of intracranial flow can persist via vessels arising extradurally. Wijdicks provides a pathophysiologic explanation for preservation of hypophyseal-pituitary axis activity in brain death, noting that perfusion to these structures arises from extracranial vessels. ${ }^{3}$ Continued cellular activity may be a manifestation of retained blood flow to these nests of cells despite intracerebral circulatory arrest. As noted by Dr. Doyle, irrespective of these explanations, the wording used in the American Uniform Determination of Death Act ("irreversible cessation of all function of the entire brain") is subject to varying interpretation.

In our recently published Canadian consensus guidelines, ${ }^{4}$ we attempt to address this conceptual and practical confusion by defining death determined by neurological criteria as follows: "The irreversible capacity for consciousness combined with the irreversible loss of all brainstem function including the capacity to breathe". This may occur as a consequence of intracranial bypertension and/or primary brainstem injury. We acknowledged that currently there are no adequate ancillary tests for the confirmation of brain death in instances of isolated primary brainstem injury.

I appland Dr. Doyle's suggestion that there is a need to reformulate the definition of brain death to reflect current clinical realities and our evolving understanding. Although difficult to influence the entrenched lexicon, we advocate abandoning the term "brain death" in favour of "the neurological determination of death (NDD)". ${ }^{4}$ As discussed in a recent editorial in the Canadian Journal of Anesthesia, ${ }^{5}$ brain death is better understood as brain arrest - the complete loss of clinical brain function. If there is a known proximate cause accounting for the brain arrest, and an absence of reversible or confounding conditions, then NDD is the corresponding process and procedure to determine this death.

Sam D. Shemie MD

Montreal Children's Hospital, McGill University

Health Centre, Montreal, Canada

E-mail: sam.shemie@muhc.mcgill.ca

\section{References}

1 Halevy A, Brody B. Brain death: reconciling definitions, criteria, and tests. Ann Intern Med 1993; 119: 519-25.

2 Bernat JL. Ethical Issues in Neurology, $2^{\text {nd }}$ ed. Boston: Butterworth Heinemann; 2002: 243-81.

3 Wijdicks EF. Brain Death. Philadelphia: Lippincott Williams \& Wilkins; 2000: 29-43.

4 Shemie SD, Doig C, Dickens B, et al. Severe brain injury to neurological determination of death: Canadian forum recommendations. CMAJ 2006; 174: S1-13.

5 Shemie SD. Brain arrest to neurological determination of death to organ utilization: the evolution of hospital-based organ donation strategies in Canada. Can J Anesth 2006; 53: 747-52.

\section{Meningismus after metaraminol administration in a patient with Familial Mediterranean fever}

To the Editor:

A 38-yr-old male was admitted to our hospital for treatment of Familial Mediterranean fever (FMF)related severe episodic abdominal pain. Familial Mediterranean fever is a hereditary inflammatory disease characterized by self-limited recurrent attacks of fever and serositis; the recurrent attacks of fever are accompanied by severe abdominal pain, arthritis and/or chest pain along with a marked increase in acute phase reactants. ${ }^{1}$ It was decided to implant a spinal cord stimulator (SCS) for pain control because of inadequate pain relief despite high-dose opioid therapy. Following the epidural placement and positioning of the SCS leads under local anesthesia, general anesthesia was administered for $s c$ implantation of the pulse generator. The patient developed hypotension during the course of the anesthetic and this was corrected with fluids and intermittent iv metaraminol boluses (cumulative dose: $10 \mathrm{mg}$ ). The procedure was completed uneventfully and the patient awakened. On 